\title{
Bitemporal hypoperfusion in transient global amnesia: 99m-Tc-HM-PAO SPECT and neuropsychological findings during and after an attack
}

Georg Stillhard, Theodor Landis, Regula Schiess, Marianne Regard, Gregorio Sialer

\begin{abstract}
We report a patient who was evaluated neuropsychologically and with single photon emission computed tomography (SPECT) during and after an episode of transient global amnesia. During the attack, there was patchy retrograde amnesia and an inability to learn both verbal and non-verbal material. SPECT showed severe bitemporal hypoperfusion. Serial neuro-psychological testing documented a rapid recovery of recognition, but delayed recovery in reproduction of learned information. Recovery of spontaneous verbal and figural fluency was even further delayed. Follow up SPECT examination showed a recovered cerebral perfusion. This case supports the hypothesis that TGA is associated with transient hypoperfusion of bilateral medial-temporal brain structures and suggests an additional involvement of structures responsible for drive and initiation.
\end{abstract}

Transient global amnesia (TGA), first recognised by Bender, ${ }^{1}$ and Guyotat and Courjon, ${ }^{2}$ is a condition of transitory amnesia without accompanying focal neurological features. TGA provides a natural experiment to study the dynamics of memory impairment. Only a few patients have been tested neuropsychologically during an attack of TGA. ${ }^{3-9}$ Usually patchy retrograde amnesia of variable extent, severe anterograde amnesia and a normal span was found, but controversy exists about the prolonged persistence of some minimal mental dysfunction despite a subjective recovery of memory. ${ }^{67}$ Despite the many reported cases, the cause of TGA remains unclear. Although transient hypoperfusion of bilateral medial-temporal cerebral structures is thought to cause TGA, bitemporal low CBF on PET $^{10}$ was reported only once and perfusion studies with single photon emission computed tomography (SPECT) are lacking. We report a patient with TGA, in whom comprehensive neuropsychological evaluation together with SPECT during the attack as well as repeated neuropsychological testing and follow up SPECTs were possible.

\section{Case history}

This 71 year old right handed woman had an uneventful medical history except for common migraine which she had experienced since adolescence. Nine years previously she had her first episode of TGA. About five hours before admission she started repeating the same questions and was unable to remember familiar events from the past few months. Neurological examination on admission was completely normal. On mental status examination she was oriented to place but not to time. She repeatedly complained of her left hemicrania as if it had just started although it had apparently persisted for hours. Questions on recent and past events concerning her personal life and important general events revealed a patchy retrograde amnesia over several months, dense for the past couple of weeks. Although she was unaware of her memory disturbance and showed little concern, there was no confabulation and her social interaction and mood appeared unchanged. Spontaneous speech was normal as were repetition, language comprehension, reading, writing, naming, left-right orientation and copying a complex figure. Mental arithmetic and copying the Necker cube were slow. The immediate recall of a short text was severely impaired and only the content of the last sentence was partly remembered. Auditory learning of 10 German nouns in three trials was severely impaired. After 15 minutes she could not recall any of the 10 items nor could she recall the copied complex figure. Cueing did not help. In addition she was given an experimental dual (verbal/figural) coding recognition memory test (DCRM). ${ }^{112}$ An EEG 24 hours after the onset of symptoms was normal except for a pronounced synchronisation on photostimulation. An extensive Doppler-ultrasound study of the vertebral and carotid vascular systems including transcranial Doppler was normal and an MRI obtained one month later showed only a slight enlargement of the right temporal horn (fig 1).

Serial neuropsychological tests were administered 15 and 38 hours, five, 12 and 22 days, and one year after the onset of the episode. They consisted of the DCRM, alternate versions of the Rey-Osterrieth complex figure, the Rey auditory-verbal test and digit span for memory assessment; also the alternate versions 
Table Summary of neuropsychological functions during TGA and course of recovery

\begin{tabular}{|c|c|c|c|c|c|c|c|}
\hline Function & $\begin{array}{l}\text { Time of assessment } \\
\text { during TGA episode }\end{array}$ & $\begin{array}{l}15 \text { hours } \\
\text { after onset }\end{array}$ & 38 hours & 5 days & 12 days & 22 days & 1 year \\
\hline $\begin{array}{l}\text { Orientation } \\
\text { Memory: } \\
\text { retrograde }\end{array}$ & $\begin{array}{l}\text { Disoriented to time } \\
\text { patchy, dense for past } 8 \text { weeks }\end{array}$ & $\begin{array}{l}\text { Normal } \\
\text { For events: normal } \\
\text { For time: defective }\end{array}$ & $\begin{array}{l}\text { Normal } \\
\text { Normal }\end{array}$ & $\begin{array}{l}\text { Normal } \\
\text { Normal }\end{array}$ & $\begin{array}{l}\text { Normal } \\
\text { Normal }\end{array}$ & $\begin{array}{l}\text { Normal } \\
\text { Normal }\end{array}$ & $\begin{array}{l}\text { Normal } \\
\text { Normal }\end{array}$ \\
\hline $\begin{array}{l}\text { anterograde } \\
15 \text { words: learning } \\
\text { recall } \\
\text { Rey complex figure of elements } \\
\text { recalled } \\
\text { recognition memory (DCRM): }\end{array}$ & complete amnesia & $\begin{array}{l}8 / 15 \\
6 / 15 \\
8 / 18\end{array}$ & $\begin{array}{l}9 \\
2 \\
6\end{array}$ & $\begin{array}{c}11^{\star} \\
8^{\star} \\
10^{\star}\end{array}$ & $\begin{array}{c}8 \\
4 \\
10^{\star}\end{array}$ & $\begin{array}{l}\text { not } \\
\text { tested } \\
\text { not } \\
\text { tested }\end{array}$ & $\begin{array}{l}13^{\star} \\
12^{\star} \\
10^{\star}\end{array}$ \\
\hline $\begin{array}{l}\begin{array}{l}\text { recognition memory }(\mathrm{DCRM}): \\
\quad \begin{array}{l}\text { storage } \\
\text { recognition }\end{array} \\
\text { Stroop interference test }\end{array} \begin{array}{l}\text { errors } \\
\text { time }(\mathrm{sec})\end{array} \\
\begin{array}{l}\text { Verbal fluency } 3 \mathrm{~min} \\
\text { Figural fluency } 3 \mathrm{~min}\end{array}\end{array}$ & $\begin{array}{l}2 / 28 \\
1 / 64\end{array}$ & $\begin{array}{l}27 / 28 \star \\
29 / 64^{\star} \\
8 \\
58 \\
14 \\
14\end{array}$ & $\begin{array}{l}23 / 28^{\star} \\
30 / 64^{\star} \\
4 \\
37^{\star} \\
11 \\
13\end{array}$ & $\begin{array}{l}22 / 28^{\star} \\
44 / 64^{\star} \\
5 \\
32^{\star} \\
13 \\
14\end{array}$ & $\begin{array}{l}22 / 28^{\star} \\
38 / 64^{\star} \\
4 \\
32^{\star} \\
12 \\
13\end{array}$ & $\begin{array}{l}25 / 28^{\star} \\
38 / 64^{\star} \\
3 \\
38^{\star} \\
17^{\star} \\
19^{\star}\end{array}$ & $\begin{array}{l}4 \\
45^{\star} \\
17^{\star} \\
18^{\star}\end{array}$ \\
\hline
\end{tabular}

$\star$ = normal compared to age matched controls.

Figure 1 Frontal sections on MRI scan ITR SE 600; TE $30 \mathrm{~ms}$ ) through the temporal lobes, showing only a slight enlargement of the right temporal horn. of the word fluency test, the same versions of the Stroop word-colour interference test and the figure fluency test for the assessment of frontal functions. To allow for age and repetition effects we later tested age matched controls. The results of the serial neuropsychological tests are summarised in the table.

During the amnesic episode her recognition memory, as measured by the DCRM, was severely impaired. The following morning, 15 hours after we first saw her, she was oriented in time and place and only vaguely remembered having been shown some drawings during the night. She was otherwise amnesic for the previous day. Events of the past two weeks were correctly remembered but misplaced in time. Her performance on the DCRM was normal. Her recall of the Rey-Osterrieth complex figure and the Rey auditory-verbal test were both pathological at 15 hours and at 38 hours, and only at five days from onset was her performance normal. All tests for frontal functions were pathological. The performance
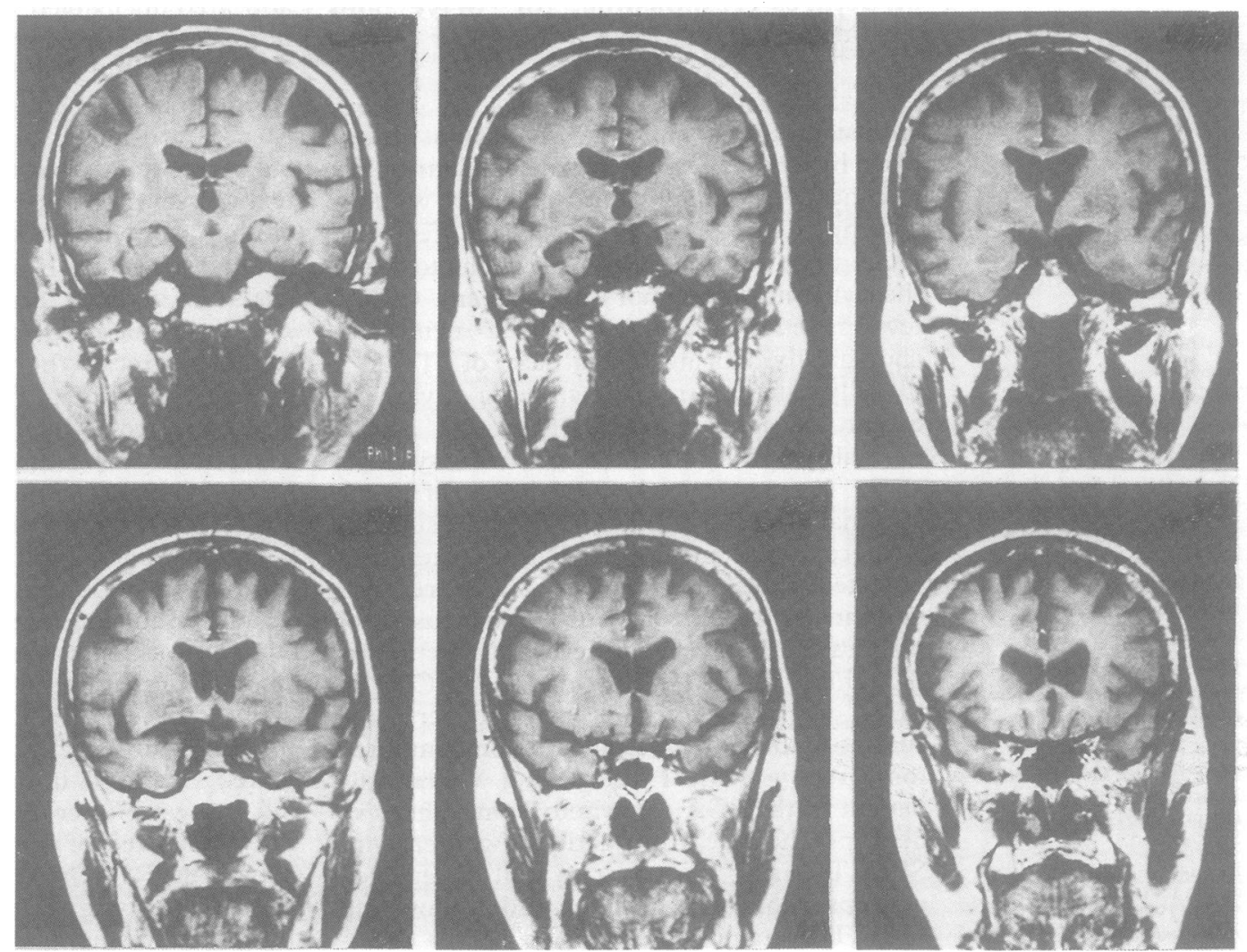

on the Stroop word-colour interference test was normal 38 hours after the onset of TGA, while the tests for word fluency and figural fluency became normal only by 22 days after the episode. Twenty two days after the episode of TGA, as well as one year later her mental status was normal.

The patient had three SPECT perfusion studies using 99m-Tc-HM-PAO (Ceretec) according to the usual procedure ${ }^{13}$ each with a dose of $600 \mathrm{MBq}$. Imaging was carried out with a rotating gamma camera (General Electric Maxi Camera $400 \mathrm{~T}$ and Picker Digital Oyma Camera 500). The first examination took place immediately after the first DCRM, about seven hours after the onset of the episode, the second after three weeks and the third after one year. Although not in identical axial planes to the showed an entirely normal cerebral perfusion. Two images showing the temporal and frontal areas from the first and the last SPECT study are shown in fig 2 . first examination, the two control SPECTs 
Figure 2 Top: two sequential images of the temporal and frontal lobes on $(99 m-T c-H M-P A O)$ SPECT during the amnesic episode showing regional hypoperfusion in both temporal lobes. The apparent bifrontal hypoperfusion (top right) may be due to bone artifacts. Bottom: SPECT one year after complete clinical recovery, showing restored regional perfusion in the temporal and frontal lobes. The slightly different cuts are due to differences in camera and head positioning.
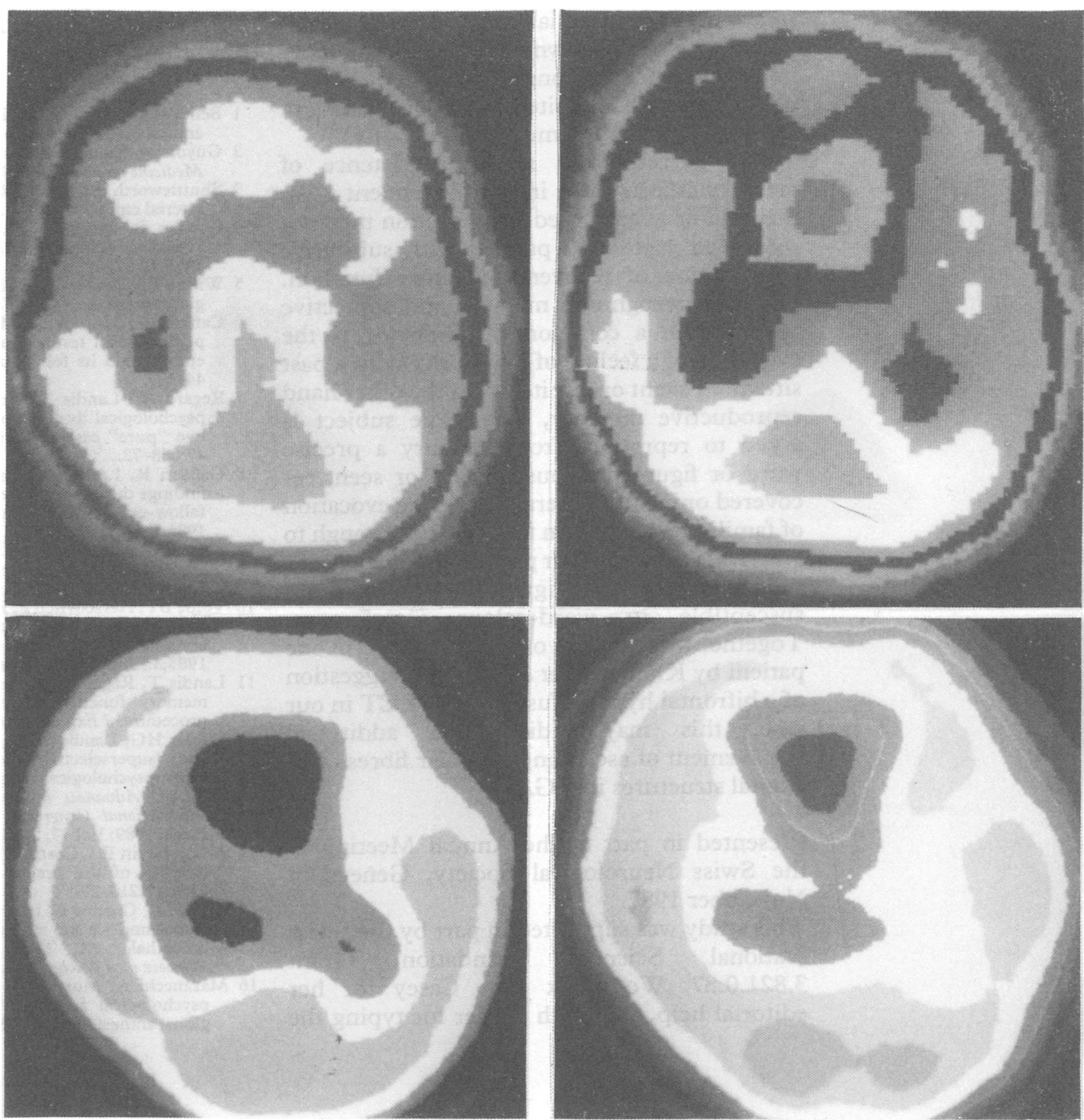

The images of the first examination (fig 2 top) during the amnesic episode showed a severe bitemporal hypoperfusion. The lower cut (top right) also suggests bifrontal hypoperfusion, however, this may be due to bone artifacts. The images of the last examination (fig 2 bottom) one year after the TGA demonstrate normalised temporal and frontal perfusion.

\section{Discussion}

We report the neuropsychological and SPECT findings of an elderly woman who was examined during and after an episode of TGA. During the attack, while she showed severe retrograde amnesia with an inability to learn both verbal and non-verbal material, she had a patchy retrograde amnesia of several months and showed a reduced verbal and figure fluency. HM-PAO SPECT demonstrated a severe bitemporal and possibly some bifrontal hypoperfusion. Repeated neuropsychological examinations over three weeks showed that delayed recognition of newly learned information was normal within 15 hours, together with a subjective feeling of "normal memory". The delayed reproduction of newly learned visual and verbal information, however, became normal only after five days and spontaneous word and figure production became normal and fluent only after three weeks. SPECT reexamination after complete mental recovery showed normal perfusion.

Ever since the early descriptions of this syndrome, epileptic activity or bilateral temporal hypoperfusion have been the two main hypotheses offered to account aetiologically for TGA. In our patient bitemporal hypoperfusion could be verified by measuring regional brain perfusion with SPECT. Three mechanisms: migraine, ${ }^{14}$ reduced flow due to atheromatous disease in the vertebrobasilar vascular system, ${ }^{15}$ and embolisation into the hippocampal vascular territories ${ }^{3}$ may account for the transient bitemporal hypoperfusion in TGA. Our patient had no vascular risk factors, and an extensive ultrasound examination of the vertebrobasilar and carotid vascular systems was normal, as was cardiological examination. On the other hand the patient had a long-standing history of common migraine and displayed severe left hemicrania, for which she was amnesic, during her episode of TGA. In the absence of evidence of atheroma or embolisation, we would favour migraine as the pathogenetic factor for this case of transient bitemporal hypoperfusion. Amnesia in TGA is by definition transient, however, the time needed for complete recovery of memory function is 
somewhat controversial since several cases of TGA have been shown to have mild memory impairment for prolonged periods of several weeks to months despite a subjective feeling of complete recovery of memory functions. ${ }^{76}$

The present case shows persistence of memory defects to be in part dependent upon the kind of testing used. Recognition memory recovered rapidly in parallel with subjective appreciation of recovered memory function. For both recognition memory and subjective appreciation a common denominator is the evocation of a feeling of familiarity with a past situation, event or test item. On the other hand reproductive memory, where the subject is asked to reproduce from memory a precise word or figure previously heard or seen, recovered only after several days. The evocation of familiarity alone is in this case not enough to reactivate the item. Our patient also displayed a reduced verbal and figure fluency, and was susceptible to word-colour interference. Together with the lack of drive reported in one patient by Kitchevski et al, ${ }^{9}$ and the suggestion of a bifrontal hypoperfusion on SPECT in our case, this may indicate an additional involvement of ascending reticular fibres or of frontal structures in TGA.

Presented in part at the Annual Meeting of the Swiss Neurological Society, Geneva in November 1987.

This study was supported in part by the Swiss National Science Foundation Grant 3.821.0.87. We thank Jane Casey for her editorial help, Elisabeth Häsler for typing the manuscript and Sepp Müller for the photography.

1 Bender MB. Syndrome of isolated episode of confusion with amnesia. J Hillside Hosp 1956;5:212-5.

2 Guyotat J, Courion J. Les ictus amnesiques. Le Journal de Medicine de Lyon 1956;37:697-701.

3 Shuttleworth EC, Wise GR. Transient global amnesia due to arterial embolism. Arch Neurol 1973;29:340-2.

4 Gordon B, Marin OSM. Transient global amnesia: an extensive case report. $J$ Neurol Neurosurg Psychiatry 1979;42:572-5.

5 Wilson RS, Koller W, Kelly MP. The amnesia of transient global amnesia. J Clin Neuropsychol 1980;2:259-66.

6 Caffarra P, Moretti G, Mazzucchi A, Parma M. NeuroCaffarra P, Moretti G, Mazzucchi A, Parma M. Neuro-
psychological testing during a transient global amnesia episode and its follow-up. Acta Neurol Scand 1981;63: 44-50.

7 Regard M, Landis T. Transient global amnesia: neuropsychological dysfunction during attack and recovery in two "pure" cases. J Neurol Neurosurg Psychiatry 1984; 47:668-72.

8 Gallassi R, Lorusso S, Stracciari A. Neuropsychological findings during a transient global amnesia attack and its follow-up. Italian Journal of Neurological Sciences 1986;7:45-9.

9 Kritchevsky M, Squire LR, Zouzounis JA. Transient global amnesia: characterization of anterograde and retrograde amnesia: characterization of anter

10 Volpe BT, Herscovitch P, Raichle ME, Hirst W, Gazzaniga MS. Cerebral blood flow and metabolism in human 1983;3:(Suppl 1) S5-S6 amnesia.

11 Landis T, Regard M, Wieser HG, Schiess R. Dissociated memory function during a new "selective" Amytal procedure. J Exp Clin Neuropsychol 1987;10:83.

12 Wieser HG, Landis T, Regard M, Schiess R. "Selective" and "superselective" temporal lobe Amytal tests: II. Neuropsychological test procedure and results. In: Bental $\mathrm{E}$, ed. Advances in Epileptology (Proc 17th Epilepsy International Congress), Jerusalem. New York: Raven Press, 1989: Vol 17, 28-33.

13 Ell PJ, Jarritt PH, Costa DC, Cullum ID, Lui D. Functional imaging of the brain. Seminars in Nuclear Medicine imaging of the

14 Caplan L, Chedru F, Lhermitte F, Mayman C. Transient global amnesia and migraine. Neurol 1981;31:1167-70.

15 Mumenthaler $M$, Treig Th. Amnestische Episoden. Schweiz med Wschr 1984;114:1163-70.

16 Mazzucchi A, Moretti G, Caffarra P, Parma M. Neuropsychological functions in the follow-up of transient global amnesia. Brain 1980;103:161-78. 